Atualidades de Pesquisa

\title{
ESCOLA E LAÇO FRATERNO: \\ REFLEXÕES SOBRE A PROPOSIÇÃO \\ DO EDUCAR PARA A SOCIABILIDADE DEMOCRÁTICA NO BRASIL ATUAL
}

Tese de Doutorado na Faculdade de Educação da Universidade Federal do Rio Grande do Sul

\author{
Autor \\ Luís Adriano Salles Souto \\ Orientadores \\ Profa. Dra. Simone Zanon Moschen \\ (Universidade Federal do Rio Grande do Sul) \\ Prof. Dr. Leandro de Lajonquière \\ (Université Paris 8) \\ Banca Examinadora \\ Prof. Dr. Hubert Vincent (Université de Rouen Normandie), \\ Profa. Dra. Ilaria Pirone (Université Paris 8), Prof. Dr. Rinaldo \\ Voltolini (Universidade de São Paulo), Profa. Dra. Fabiana Marcello \\ (Universidade Federal do Rio Grande do Sul)
}


[1

sta tese busca refletir sobre as ações educativas que têm como fim a promoção da "sociabilidade democrática" - uma das diretrizes da escolarização no Brasil - a partir da investigação sobre os impasses relativos ao laço fraterno e da afirmação de que a escola pode ser compreendida como dispositivo societário implicado com o que denominamos de "socialização do narcisismo". Três linhas de trabalho são, para isso, requeridas. A primeira, que se dedica às vicissitudes das fratrias, recupera o debate estabelecido entre Einstein e Freud, em 1932, sobre os "fatores psicológicos de peso" associados às distintas faces da rivalidade e da agressividade. Como pensar o aprofundamento de uma ética democrática quando se afirma que a relação do sujeito com o semelhante é marcada por um antagonismo constitutivo e, por isso, intransponível? A segunda linha resgata das teorias de Claude Lefort e de Castoriadis noções que nos ajudam a compreender, em termos éticos e políticos, o que significa a invenção da democracia no Ocidente. A terceira linha de trabalho destaca como a conflitiva do sujeito com o semelhante pode ser compreendida através dos processos identificatórios requeridos no processo de subjetivação da cria humana. 